\title{
Presence of anti-Leishmania (Viannia) braziliensis antibodies in blood donors in the West-Central region of the State of Paraná, Brazil
}

\author{
Lais de Souza Braga ${ }^{[1]}$, Taísa Rocha Navasconi ${ }^{[1]}$, Elen Paula Leatte ${ }^{[2]}$, \\ Cissiara Manetti Skraba ${ }^{[1]}$, Thaís Gomes Verzignassi Silveira ${ }^{[3]}$ \\ and Rejane Cristina Ribas-Silva ${ }^{[4]}$
}

[1]. Programa de Pós-Graduação em Ciências da Saúde, Universidade Estadual de Maringá, Maringá, Paraná, Brazil. [2]. Programa de Pós-Graduação de Biociências e Fisiopatologia, Universidade Estadual de Maringá, Maringá, Paraná, Brazil. [3]. Departamento de Análises Clínicas e Biomedicina, Universidade Estadual de Maringá, Maringá, Paraná, Brazil. [4]. Departamento de Biomedicina, Faculdade Integrado de Campo Mourão, Campo Mourão, Paraná, Brazil.

\begin{abstract}
Introduction: Serological screening in blood banks does not include all transmittable diseases. American cutaneous leishmaniasis (ACL) has a high detection rate in the municipalities of the State of Paraná. Methods: This study analyzed the presence of antiLeishmania braziliensis antibodies in 176 blood donors who live in these endemic areas. The variables were analyzed with the $\chi^{2}$ test and Stata 9.1 software. Results: Twenty (11.4\%) samples were positive for the presence of anti-L. braziliensis antibodies. Conclusions: The high percentage of donors with anti-Leishmania spp. antibodies indicates the need to study the risk of ACL transmission through blood donors.
\end{abstract}

Keywords: Leishmaniasis. Blood donors. Asymptomatic infections.

Cutaneous leishmaniasis is included in the list of neglected tropical diseases produced by the World Health Organization ${ }^{(1)}$. It is considered a public health problem because of its high rate of detection and ability to produce deformities ${ }^{(2)}$. Approximately 1-1.5 million cases are registered per year worldwide $^{(2)}$. In the affected countries, investment in prevention and control strategies are essential to ensure the well-being of the population. Brazil recorded approximately 635,399 cases of American cutaneous leishmaniasis (ACL) in the Sistema de Informação de Agravos de Notificação (SINAN Net) ${ }^{(3)}$. American cutaneous leishmaniasis cases have been recorded in 276 municipalities in State of Paraná, Brazil. The Northwest, West Central, and North Central regions of Paraná are endemic areas for ACL ${ }^{(4)}$. The main etiological agent of ACL in Brazil is Leishmania (Viannia) braziliensis ${ }^{(2)}$.

The clinical manifestations of ACL include the cutaneous form, characterized by granular-base ulcers and protruding edges, and the mucocutaneous form, characterized by serious and crippling metastases in the nasal mucosa ${ }^{(5)}$. Research in endemic areas has also shown the existence of asymptomatic and subclinical forms of $\mathrm{ACL}^{(6)}$.

Corresponding author: Dra. Rejane Cristina Ribas-Silva. Rodovia BR 158 KM 207, Campo Mourão, Paraná, Brasil.

Phone: 5544 3518-2564

e-mail: coord.biomedicina@grupointegrado.br

Received 5 February 2015

Accepted 5 May 2015
The laboratory diagnosis of ACL can be made through microscopic examination, biopsy culture, animal inoculation, polymerase chain reaction detection, and immunological methods, including the Montenegro skin test, indirect immunofluorescence assay (IFA), and enzyme immunoassay (EIA) ${ }^{(7)}$.

The transmission of the pathogen, in particular, through blood transfusion may occur when the serological screening does not include the said agent, or the test used is not sensitive enough to detect the pathogen in the blood donor and the recipient is not immunologically competent enough ${ }^{(8)}$.

The Ministry of Health recommends that the serological screening of blood donors include tests for human immunodeficiency virus type 1 (HIV-1), human immunodeficiency virus type 2 (HIV-2), human T-lymphotropic virus type I (HTLV-I), human T-lymphotropic virus type II (HTLV-II), hepatitis C, hepatitis B, Trypanosoma cruzi, and Treponema pallidum. For immunosuppressed patients, a cytomegalovirus test is also performed. In endemic areas, a malaria test is additionally performed. Leishmaniasis is not included in the serological screening of blood donors. The expansion of the serological screening might exclude the risk of transmission of ACL. Thus, the screening of candidates for blood donations does not guarantee a completely safe transfusion because some diseases that can potentially cause transmission to susceptible recipients may be overlooked $^{(8)}$.

Campo Mourão is located in the Mesorregião do Centro Ocidental Paranaense, which is considered an endemic area 
for ACL. The Hemonúcleo Regional of Campo Mourão receives blood donors from 25 municipalities of Comunidade dos Munícipios da Região de Campo Mourão. The aim of the present study was to analyze samples from blood donors who presented at the Hemonúcleo Regional of Campo Mourão for the presence of anti-Leishmania braziliensis antibodies by using the EIA test.

Serum samples from 176 blood donors who presented at the Hemonúcleo Regional of Campo Mourão from March to April 2011 were analyzed. Exclusion criteria for the samples of this study were the same as recommended for the exclusion of donors in blood banks ${ }^{(9)}$. The samples were stored at $-20^{\circ} \mathrm{C}$ until use.

Data including sex, age, municipality of residence, residence area, education level, ethnicity, length of time as a blood donor, and frequency of donations per year, were obtained from the blood donors' records. All participants received information on the study and those who agreed to participate, signed consent forms.

Enzyme immunoassay was performed as described by Yoneyama et al. ${ }^{(10)}$ using antigens from promastigotes of L. braziliensis (MHOM/BR/1987/M11272). Briefly, plates were sensitized with the extract crude antigen $(10 \mu \mathrm{g} /$ well $)$ diluted in $0.1 \mathrm{M}$ carbonate-bicarbonate buffer ( $\mathrm{pH}$ 9.6). The sera were diluted 1:150 and added to the plate. The reaction was developed with anti-human immunoglobulin G-peroxidase conjugate (Sigma-Aldrich, St. Louis, MO, USA) and $O$-phenylenediamine dihydrochloride (Sigma-Aldrich). The reaction was stopped with the addition of $3 \mathrm{M} \mathrm{H}_{2} \mathrm{SO}_{4}$, and absorbance was read at $492 \mathrm{~nm}$ with an ASYS v1.4 microplate reader (Eugendorf, Austria). Each sample was analyzed in duplicate. The samples were considered positive when the average absorbance was $>0.68$ (i.e., cutoff value). Positive and negative controls for all plates were included.

Association between the epidemiological variables and serological results were analyzed using the $\chi^{2}$ test and Stata 9.1 software. The level of significance was $5 \%(\mathrm{p}<0.05)$.

The experimental protocol was approved by the Comitê Permanente de Ética em Pesquisa Envolvendo Seres Humanos, Universidade Estadual de Maringá (Report 303/2011).

The socio epidemiological data of the blood donors are shown in Table 1. Of the 176 samples analyzed, 20 (11.4\%) were positive for anti-Leishmania braziliensis antibodies.

Table 1 shows that positive results were more prevalent in donors $>50$ years old $(20 \%)$. No significant difference was found in the distribution of positive results among the age groups $(\mathrm{p}=0.206)$.

The prevalence of seropositivity in blood donors was higher in women $(11.5 \%)$, but no significant differences between sexes were found in the distribution of positive results $(\mathrm{p}=0.972$; Table 1).

The higher prevalence of anti-Leishmania antibodies was observed in blood donors living in Campina da Lagoa (22.6\%). However, no significant difference in positive results was found among the municipalities of residence $(p=0.137$; Table 1$)$.

Regarding the residence area of the blood donors, similar prevalence was observed among donors living in rural and urban areas $(12.5 \%$ and $10.2 \%$, respectively; $\mathrm{p}=0.835)($ Table $\mathbf{1})$.
The positive serology for ACL was more prevalent in blood donors with basic education (12.1\%) versus $10.4 \%$ for high school and higher education, but the difference was not statistically significant $(p=0.745)$ (Table 1$)$.

The predominant ethnic group among the blood donors was Caucasian (65.3\%); however, there was no statistically significant difference in the prevalence of ACL among the groups $(\mathrm{p}=0.897)$ (Table 1).

Table 2 shows that regarding the time and number of donations, we found that the highest prevalence of ACL was observed in those who had donated blood for more than 10 years (19\%) and in first-time donors (15.4\%). However, no statistically significant difference was seen $(p=0.401$ and $\mathrm{p}=0.169$, respectively).

The high prevalence (11.4\%) of seropositivity for antiL.braziliensis antibodies in blood donors at the Hemonúcleo Regional of Campo Mourão causes concern, since the blood recipients may be at risk of being infected.

Mestra et al. ${ }^{(11)}$ reported a case of transmission of visceral leishmaniasis by Leishmania (Leishmania) mexicana via blood transfusion, although this species is being associated with cases of cutaneous leishmaniasis. It indicates the risk of transmission of ACL through blood transfusion. To our knowledge, this is the first study that shows the occurrence of anti-L. braziliensis antibodies in blood donors in an endemic area.

The clinical and epidemiological screening of blood donors minimizes the risk of disease transmission from donor to recipient, but does not detect the presence of all diseases that are transmissible through blood transfusion. The association of the clinical and epidemiological with the serological screening can improve the blood donor selection by detection of asymptomatic forms of diseases that are transmissible through blood. Fukutani et al. ${ }^{(12)}$, detected Leishmania kinetoplast deoxyribonucleic acid (kDNA) minicircles in blood donors in an endemic area for visceral leishmaniasis, indicating that, in addition to antibodies, these asymptomatic individuals can harbors the parasite, representing risk of transmission to the recipient.

Previous studies have reported the presence of asymptomatic and subclinical cases of ACL in endemic areas ${ }^{(6)(13)}$. The development of ACL requires inoculation with the promastigote forms, which enter the insect vector from the host's skin. These forms transform into amastigotes, and they may be present in blood cells in the host ${ }^{(5)}$. If blood donors are carriers of the parasite, then blood bags may contain amastigote forms of the parasite. Further studies are needed to demonstrate the possibility of parasite development in the blood recipient. Moreover, if hematogenous and/or lymphatic dissemination of the parasite can be the cause of mucocutaneous leishmaniasis ${ }^{(5)(14)}$, then recipients of blood that contains amastigotes of $L$. braziliensis could develop this form of the disease.

Although the blood analyzed in the present study showed the presence of anti-L. braziliensis antibodies, we did not determine the presence of parasites in peripheral blood from the donor. The resistance of the parasite to the conditions of processing and storing blood bags is yet unknown. Whole blood and blood fractions are maintained at low temperatures ${ }^{(15)}$. 
TABLE 1 - Socio-epidemiological data and results of enzyme immunoassay of 176 blood donors from Hemonúcleo Regional of Campo Mourão, State of Paraná, Brazil.

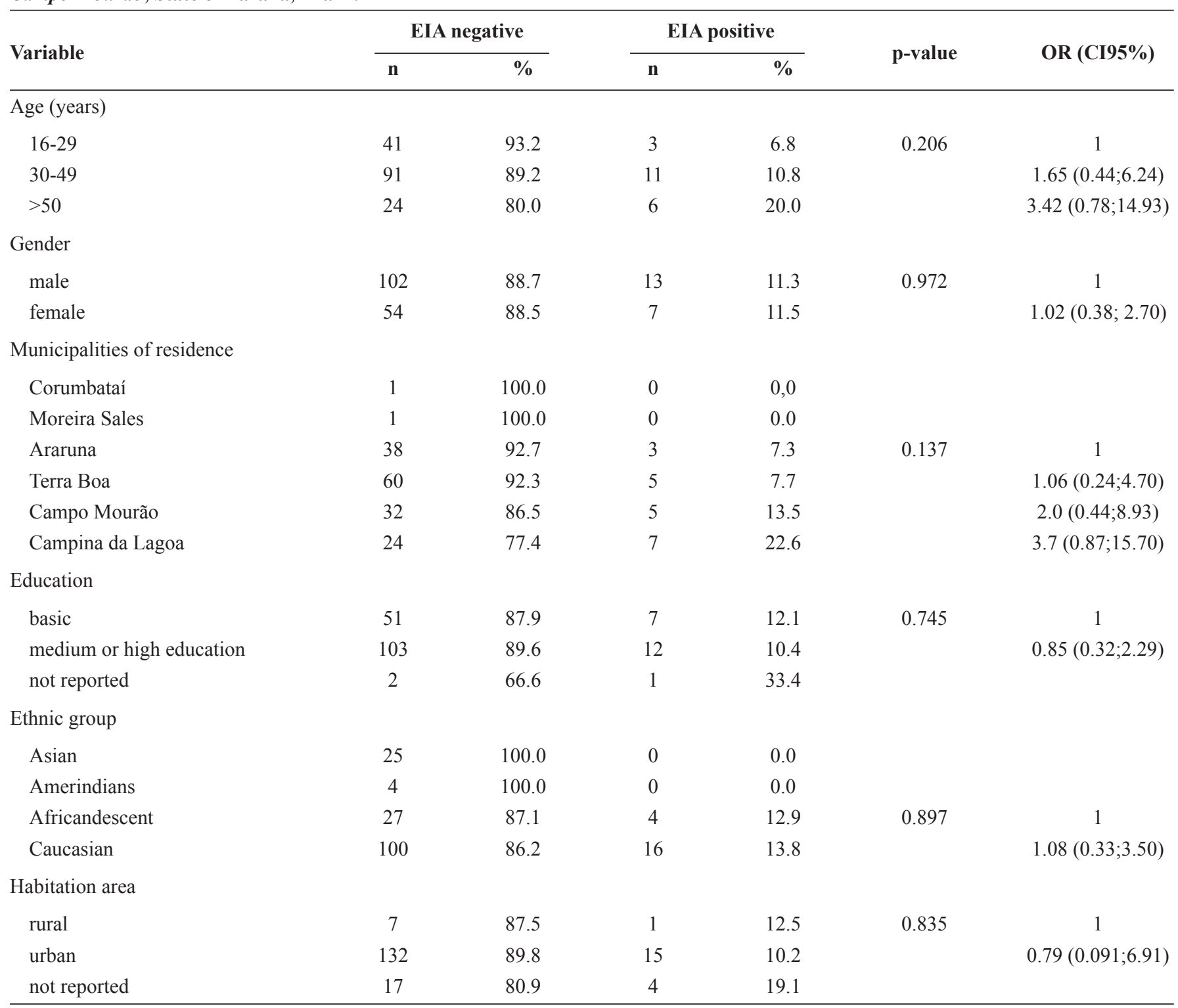

EIA: enzyme immunoassay; OR: odds ratio; CI95\%: confidence interval 95\%.

TABLE 2 - Socio epidemiological data and results of enzyme immunoassay of 176 blood donors from Hemonúcleo Regional of Campo Mourão, State of Paraná, Brazil.

\begin{tabular}{|c|c|c|c|c|c|c|}
\hline Variable & \multicolumn{2}{|c|}{ EIA negative } & \multicolumn{2}{|c|}{ EIA positive } & p-value & OR (CI95\%) \\
\hline \multicolumn{7}{|c|}{ Time as blood donor(years) } \\
\hline $0-5$ & 102 & 88.7 & 13 & 11.3 & 0.401 & 1 \\
\hline $6-10$ & 37 & 92.5 & 3 & 7.5 & & $0.64(0.17 ; 2.36)$ \\
\hline$>10$ & 17 & 81.0 & 4 & 19.0 & & $1.85(0.54 ; 6.33)$ \\
\hline \multicolumn{7}{|c|}{ Frequency of donations per year } \\
\hline $1^{\text {st }}$ donation & 44 & 84.6 & 8 & 15.4 & 0.169 & 1 \\
\hline 1-3 donation & 128 & 91.4 & 12 & 8.6 & & $0.52(0.20 ; 1.35)$ \\
\hline not reported & 4 & 100.0 & 0 & 0.0 & & \\
\hline
\end{tabular}

EIA: enzyme immunoassay; OR: odds ratio; CI95\%: confidence interval 95\%. 
American cutaneous leishmaniasis is an important public health problem. The high percentage of blood donors who tested positive for anti-L.braziliensis antibodies is concerning. The present results indicate the need to study the risk of ACL transmission through blood transfusion from donors with asymptomatic forms of the disease. There are few reports in the literature about infection with Leishmania sp. through blood transfusion. Investigation of blood transfusion history should be done in every patient with a diagnosis of ACL, to check the possibility by transmission through blood. In addition, more studies are needed to determine whether the transmission of ACL can occur through blood infected with Leishmania sp. Thus, there were more evidences to support the inclusion the detection of anti-Leishmania sp. antibody to serological screening in blood banks in endemic areas.

\section{ACKNOWLEDGMENTS}

We thanks the people of the Leishmaniases Laboratory, Department of Clinical Analyses and Biomedicine, State University of Maringá.

\section{CONFLICT OF INTEREST}

The authors declare that there is no conflict of interest.

\section{REFERENCES}

1. World Health Organization. Neglected tropical diseases (Internet) (place unknown): Neglected tropical diseases (cited 2015 Mar 15). Available at: http://www.who.int/neglected_diseases/diseases/en/

2. Ministério da Saúde. Manual de vigilância da leishmaniose tegumentar americana. Brasília (DF): Ministério da Saúde; 2010.

3. Ministério da Saúde. Departamento de informática do SUS (Internet). Leishmaniose tegumentar americana: casos confirmados notificados no Sistema de Informação de Agravos de Notificação-SINAN Net
(Cited 2012 April 29). Available at: http://dtr2004.saude.gov.br/ sinanweb/tabnet/dh?sinannet/lta/bases/ltabrnet.def

4. Lima AP, Minelli L, Teodoro U, Comunello E. Tegumentary leishmaniasis distribution by satellite remote sensing imagery, in Paraná State, Brazil. An Bras Dermatol 2002; 77:681-692.

5. Gontijo B, Carvalho MLR. Leishmaniose tegumentar americana. Rev Soc Bras Med Trop 2003; 36:71-80.

6. Arraes SMAA, Marini MT, Martello D, Silveira TGV, Lonardoni MVC, Nanni MR. Serological investigation of subclinical cutaneous leishmaniasis cases following an outbreak in an endemic area. Rev Soc Bras de Med Trop 2008; 41:205-208.

7. Gomes CFL. Protozoologia: Gênero Leishmania. In: Neves DP, editor. Parasitologia Dinâmica, $3^{\text {rd }}$ ed. São Paulo: Editora Atheneu; 2009. p. $99-125$.

8. Carrazzone CFV, Brito AM, Gomes YM. Importância da avaliação sorológica pré-transfusional em receptores de sangue. Rev Bras Hematol Hemoter 2004; 26:93-98.

9. Ministério da Saúde. Portaria $\mathrm{n}^{\circ}$ 2.712, 12 novembro 2013. Redefine o regulamento técnico de procedimentos hemoterápicos. (internet). Diário Oficial da União 12 novembro 2013. (Cited 2015 March 13). Available at: http://bvsms.saude.gov.br/bvs/saudelegis/gm/2013/ prt2712_12_11_2013.html

10. Yoneyama KAG, Peder LD, Lonardoni MVC, Silveira TGV. Diagnosis of American cutaneous leishmaniasis by enzyme immunoassay in patients from northern Paraná state, Brazil. Braz J Infect Dis 2007; 11:360-364.

11. Mestra L, Lopez L, Robledo SM, Muskus CE, Nicholls RS, Velez ID. Transfusion-transmitted visceral leishmaniasis caused by Leishmania (Leishmania) mexicana in an immunocompromised patient: a case report. Transfusion 2011; 51:1919-1923.

12. Fukutani KF, Figueiredo V, Celes FS, Cristal JR, Barral A, BarralNetto M, et al. Serological survey of Leishmania infection in blood donors in Salvador, Northeastern Brazil. Infect Dis (Lond) 2014; 14:422.

13. Follador I, Araújo C, Bacellar O, Araújo CB, Carvalho LP, Almeida RP, et al. Epidemiologic and immunologic findings for the subclinical form of Leishmania braziliensis infection. Clin Inf Dis 2002; 34:E54-E58.

14. Marsden PD. Mucosal leishmaniasis ("Espundia" Escomel, 1911). Trans R Soc Trop Med Hyg 1986; 80:859-876.

15. Rede de Serviços Tecnológicos para Sangue e Hemoderivados. Manual para controle da qualidade do sangue total e hemocomponentes. São Paulo: RedSang-SIBRATEC; 2011. 